\title{
Proposta de elemento de integração para a interface entre alvenaria estrutural e esquadria
}

\author{
Proposal of an integration element for the interface \\ between structural masonry and openings
}

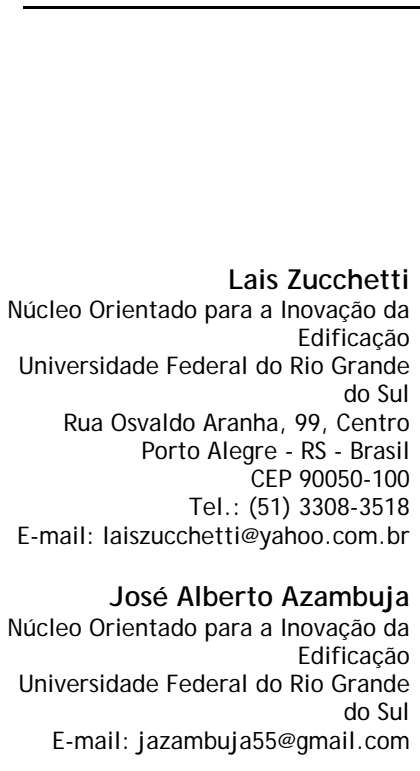

Luis Carlos Bonin Núcleo Orientado para a Inovação da Edificação Universidade Federal do Rio Grande E-mail: luis.bonin@ufrgs.br

J oão Ricardo Masuero Centro de Mecânica Aplicada e Computacional Universidade Federal do Rio Grande do Sul

E-mail: joao.masuero@ufrgs.br

Inácio Benvegnu Morsch Centro de Mecânica Aplicada e Computacional Universidade Federal do Rio Grande

E-mail: morsch@ufrgs.br

Angela Borges Masuero Núcleo Orientado para a Inovação da Edificação Universidade Federal do Rio Grande

E-mail: angela.masuero@ufrgs.br

Dense Carpena Coitinho Dal Molin Núcleo Orientado para a Inovação da Edificação Universidade Federal do Rio Grande

E-mail: dmolin@ufrgs.br

Recebido em 21/10/10 Aceito em 24/08/11

\section{Lais Zucchetti \\ J osé Alberto Azambuja \\ Luis Carlos Bonin \\ J oão Ricardo Masuero \\ Inácio Benvegnu Morsch \\ Angela Borges Masuero \\ Denise Carpena Coitinho Dal Molin}

Resumo

A

utilização de sistemas modulares na indústria da construção tem crescido de forma acentuada nos últimos anos no Brasil, sendo que, dentre estes, se destaca o sistema construtivo de alvenaria estrutural. Entretanto, diversos estudos apontam uma alta incidência de manifestações patológicas relacionadas a este sistema. A interface entre alvenaria e esquadria é um dos locais de maior incidência de problemas, além de representar um gargalo construtivo, pela necessidade de realização de inúmeras atividades que dependentes da mesma. O presente artigo apresenta o processo de desenvolvimento de uma nova solução para este problema, denominada elemento de integração, incluindo sua definição geométrica, funcional e conceitual, bem como a produção de protótipos virtuais e físicos (com diferentes materiais). Ao longo do desenvolvimento de diferentes modelos, foram realizadas avaliações pela equipe de projeto, a partir das quais foram introduzidas melhorias. Ao todo, foram produzidos 4 modelos virtuais, 3 modelos físicos na escala 1:1, e uma parede experimental. Os principais resultados apontam para a viabilidade e adequação da proposta ao sistema construtivo, bem como identificam o possível aumento de construtibilidade do sistema como um todo a partir da aplicação do elemento desenvolvido.

Palavras-chave: Alvenaria estrutural. Desenvolvimento do produto. Esquadrias. Elemento de integração.

\section{Abstract}

Nowadays, the use of modular systems in the construction industry has grown substantially in Brazil, and, among them, the structural masonry system stands out. However, several studies point out the high incidence of pathological manifestations related to this system, being the interface between masonry and windows one of the places with the highest number of problems, besides being a bottleneck in the production process, since several activities depend on that interface. This article presents the development process of a new solution, named integration element, its geometrical, functional, and conceptual definitions, as well as the production of virtual and physical prototypes (using different materials). The project team also conducted evaluations of the solutions after the construction of each prototype, when modifications were made. Four virtual and three physical prototypes were produced, and an experimental wall was built. The main results show the feasibility and adequacy of the proposed solution to the constructive system, as well as identify the potential increase of constructability of the system as a whole with the use of the proposed element.

Keywords: Structural masonry. Interface. Openings. Product development. Integration element. 


\section{Introdução}

Buscando diminuir os índices de déficit habitacional, o governo federal lançou diversos programas de provisão habitacional, tais como PAR e Minha Casa Minha Vida, que utilizam quase que exclusivamente a alvenaria estrutural como sistema construtivo (RICHTER, 2007).

Entretanto, diversas pesquisas apontam o aparecimento de manifestações patológicas relacionados a esse sistema construtivo (RICHTER, 2007; ALEXANDRE, 2008; BRITO, 2009), normalmente associadas a fissuração, o que, segundo Holanda Junior (2002), acontece pela fragilidade e baixa resistência a tração dos materiais e componentes construtivos utilizados.

Moch (2009) constatou em sua pesquisa que $24 \%$ das manifestações patológicas em edificações de alvenaria estrutural estão relacionadas à interface alvenaria-esquadria e seu entorno, indicando uma área realmente problemática das construções, já que podem comprometer a habitabilidade, a estética e/ou a estrutura da alvenaria.

Além dos problemas patológicos, os procedimentos ligados à preparação do vão e colocação das esquadrias representam um gargalo construtivo no sistema de alvenaria estrutural, pela necessidade de execução de diversas etapas construtivas que apresentam dependência e de profissionais especializados na instalação das janelas (AZAMBUJA et al., 2008). Essa constatação contraria a atual tendência da construção civil de simplificação dos procedimentos técnicos e operacionais, de desenvolvimento e aplicação de novas soluções e de redução de custos e do desperdício das construções, visando a melhores níveis de produtividade e qualidade (CÉSAR; ROMAN, 2006; MAGALHÃES, 2004).

A busca por economia, industrialização e racionalização na construção civil tem contribuído para a difusão da alvenaria estrutural como processo construtivo de grande importância econômica e social, cuja utilização proporciona vantagens como rapidez na execução, maior padronização de procedimentos e menor desperdício em obra quando comparado aos processos construtivos tradicionais (JOAQUIM, 1999; MEDEIROS; SABBATINI, 1993). Aliado a esses benefícios, esse sistema não exige grandes investimentos e imobilização de capital para a aquisição de equipamentos e plantas industriais (ALY; SABBATINI, 1994). Dentro desse contexto surgiu o projeto Compohis, que trata de transferência de tecnologia de materiais e componentes para a produção de novos elementos para a construção de habitação de interesse social e tem como objetivo principal desenvolver um componente de conectividade para sistemas construtivos de alvenaria modular, visando à melhoria da qualidade e à racionalização do processo construtivo. O projeto faz parte do programa de tecnologia da habitação, implantado pela Financiadora de Estudos e Projetos (Finep), incluindo-se na rede de desenvolvimento e difusão de tecnologias construtivas para a habitação de interesse social, com enfoque na coordenação modular.

Para um melhor entendimento, este trabalho é divido em três etapas principais:

(a) uma inicial, que engloba o desenvolvimento e a aplicação da metodologia, resultando em uma proposta inicial de solução, denominada elemento de conexão (EC);

(b) outra intermediária, que inclui a produção de protótipos físicos e virtuais e as modificações da proposta inicial, a partir de avaliações por parte do grupo de pesquisa, denominando esse refinamento da solução como elemento de integração (EI); e

(c) uma final, que envolve a utilização da solução em uma construção experimental, buscando identificar sua real aplicabilidade no sistema construtivo proposto.

Dessa forma, a primeira fase caracteriza-se pelo desenvolvimento e aplicação da metodologia para o desenvolvimento de componentes na construção proposta por Azambuja et al. (2008). Essa metodologia baseou-se em dados coletados nas primeiras fases do projeto por Richter (2007) e Moch (2009). Nessa etapa inicial ainda foram definidos a área de intervenção, o tipo de abordagem do problema levantado, os requisitos de desempenho, os materiais e possíveis geometrias do elemento construtivo.

A partir da finalização da metodologia, o elemento foi definido geometricamente com o auxílio de simulações computacionais via elementos finitos e modelado através de programas $\mathrm{CAD}$, gerando a primeira maquete virtual, que foi utilizada para a simulação das sequências construtivas necessárias para a construção de uma parede com a utilização do elemento. Nessa etapa, a solução proposta passou a denominar-se elemento de integração, por motivos que ficarão claros ao longo do trabalho.

A partir desses modelos, foram gerados três protótipos físicos, sendo o primeiro em MDF, e os outros dois em GRC (glassfiber reinforced concrete), material escolhido para a produção do 
EC. A produção do terceiro modelo em GRC finaliza a segunda etapa.

A cada nova maquete virtual e física foram realizadas avaliações pelo grupo, buscando identificar os pontos positivos que seriam adotados e os negativos para os quais se faziam sugestões, gerando modificações mediante propostas de novas soluções.

Com o último protótipo em GRC produzido, construiu-se uma parede experimental em tamanho real, buscando identificar a adaptabilidade da nova solução construtiva ao sistema construtivo e dos operários com o EI, fechando assim a etapa final.

\section{Metodologia da pesquisa}

A metodologia utilizada no desenvolvimento de cada etapa da pesquisa bem como os resultados de cada uma dessas fases são abordados a seguir. Inicialmente, apresentam-se a metodologia utilizada para a seleção do material e a geometria do EC, bem como as primeiras definições acerca dos arranjos funcionais, conceituais e formais da proposta.

Em seguida são mostrados os métodos utilizados para a modelagem virtual e física, assim como as modificações propostas e as soluções adotadas a cada nova produção e consequente avaliação do EI.

Por fim, expõe-se a construção experimental desenvolvida, com as principais contribuições e entraves para a implementação da nova solução.

\section{Metodologia de desenvolvimento de novos componentes}

A partir dos dados coletados nas primeiras etapas do projeto (MOCH, 2009; RICHTER, 2007), a equipe de pesquisa elegeu como área de intervenção a esquadria e seu entorno, tendo como problema aparente as manifestações patológicas no entorno das aberturas dos vãos.

Essa definição de problema gerou diversas propostas de soluções que atingiam pontualmente a origem de cada manifestação, ou que resolviam de forma integrada e com um único elemento as diferentes causas de fissuras. Diante de inúmeras tentativas individuais de resolução de fissuras desenvolvidas, que apresentaram desempenho não satisfatório e não contribuíram para a racionalização e melhoria da produtividade, adotou-se pelo grupo uma nova abordagem, que compreendeu o problema real como o de solução de continuidade na borda do vão. Essa abordagem unificada para a resolução do problema levou ao desenvolvimento de um elemento que solucionasse ao mesmo tempo as manifestações patológicas e os problemas de produtividade identificados no projeto (AZAMBUJA et al., 2008).

A partir dessa definição foram identificados os requisitos de desempenho para o adequado funcionamento do componente. Eles foram compilados em cinco grandes grupos, a saber, construtibilidade, economicidade, habitabilidade, segurança e sustentabilidade, sendo os três últimos utilizados pela norma brasileira de desempenho NBR 15575 (ABNT, 2008), e os dois primeiros sugeridos pelo grupo, dada a relevância que apresentam na pesquisa.

\section{Seleção do material}

O material utilizado para a produção do elemento foi escolhido inicialmente mediante o cruzamento entre informações acerca de cada um dos requisitos de desempenho e características desejáveis ao componente elencadas pelo grupo de pesquisa. Para isso, cada um dos cinco grupos de requisitos de desempenho foi subdividido em condições específicas de desempenho, que foram selecionadas pela relevância que apresentavam considerando o comportamento do elemento (Quadro 1). Nessa fase também foram selecionadas características desejáveis dos materiais para a produção do elemento (seleção rosa do Quadro 1). O resultado desse cruzamento foi uma matriz de interações positivas e negativas, que serviu de auxílio para a seleção de materiais (Quadro 1). Dessa forma, identificou-se que as características que apresentam maior número de interações positivas e negativas são, respectivamente, a moldabilidade e a fragilidade.

A partir desse resultado, foram selecionados cinco materiais construtivos para a produção do elemento (Quadro 2), concreto, madeira, GRC, aço carbono e alumínio.

As propriedades desses materiais foram então avaliadas de acordo com as características dos materiais (Quadro 2), através de pontuação que variava de 0 a 10 , sendo estes, respectivamente, o pior e o melhor desempenho (Quadro 2). Nesse quadro as relações consideradas positivas no Quadro 1 foram somadas, e as negativas, subtraídas. Através desse método, ficou demonstrado que o material GRC apresentou o melhor resultado, com 28 pontos, seguido pelo aço carbono (26 pontos) e alumínio (17 pontos). Dessa forma, o GRC foi o material escolhido para a produção do componente. 


\begin{tabular}{|c|c|c|c|c|c|c|c|c|c|c|c|c|}
\hline & \multicolumn{12}{|c|}{ CARACTERÍSTICAS } \\
\hline REQUISITOS & 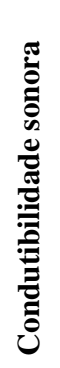 & 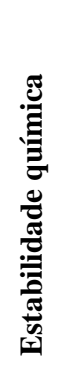 & 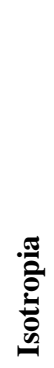 & 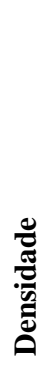 & 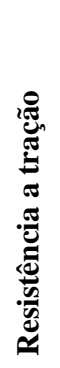 & 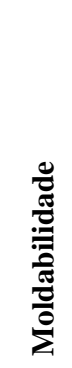 & 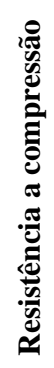 & 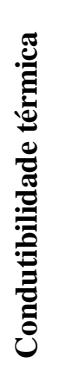 & 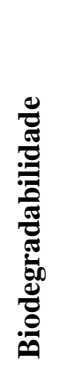 & 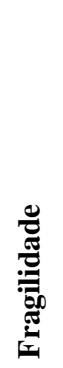 & 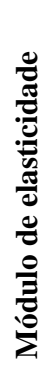 & 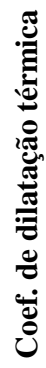 \\
\hline Ajuste dimensional & & & & & & + & & & & - & + & - \\
\hline Gabarito do vão & & & & & & + & & & & & + & - \\
\hline Fixação da esquadria & & & & & + & + & + & & - & - & + & - \\
\hline Barreira às intempéries & & + & & & & + & & & - & & & \\
\hline Isolamento térmico & & & & - & & & & - & & & & - \\
\hline Isolamento acústico & - & & & - & & & & & & & & \\
\hline Estabilidade do vão & & & + & + & + & + & + & & - & - & + & - \\
\hline Absorção de dilatação térmica & & & & & & & & - & & - & & - \\
\hline $\begin{array}{l}\text { Absorção de variações } \\
\text { dimensionais }\end{array}$ & & & & & & + & & & & - & + & - \\
\hline Acabamento interno & & & & & & + & & & & - & & \\
\hline Acabamento externo & & & & & & + & & & & - & & \\
\hline Resolução de fissuras & & & + & & + & & + & & & - & & \\
\hline RESULTADO & - & + & + & & + & $\begin{array}{l}+ \\
*\end{array}$ & + & - & - & - & $\begin{array}{l}+ \\
*\end{array}$ & $\bar{*}$ \\
\hline
\end{tabular}

Quadro 1 - Matriz de interações entre características de materiais e requisitos de desempenho do EI Fonte: Azambuja et al. (2008).

\begin{tabular}{|c|c|c|c|c|c|c|c|c|c|c|c|c|c|}
\hline & \multicolumn{12}{|c|}{ CARACTERÍSTICAS } & \multirow[b]{2}{*}{ 身 } \\
\hline MATERIAIS & 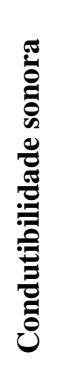 & 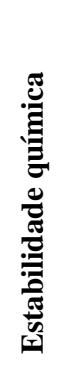 & 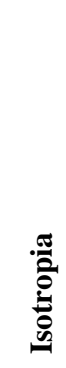 & 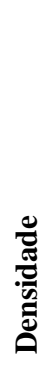 & 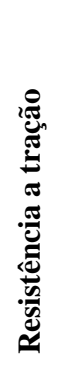 & 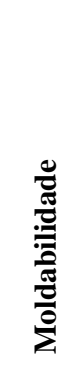 & 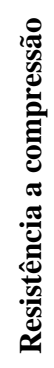 & 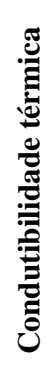 & 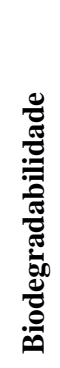 & 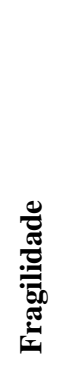 & 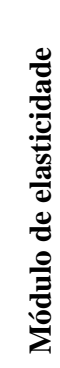 & 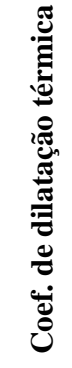 & \\
\hline Concreto & 6 & 7 & 5 & 5 & 3 & 7 & 5 & 5 & 3 & 7 & 5 & 6 & 4 \\
\hline Madeira & 3 & 3 & 2 & 2 & 5 & 7 & 3 & 3 & 8 & 3 & 2 & 4 & 3 \\
\hline GRC & 6 & 8 & 8 & 6 & 7 & 9 & 7 & 6 & 2 & 4 & 7 & 6 & $\begin{array}{l}2 \\
8\end{array}$ \\
\hline Aço carbono & 8 & 4 & $\begin{array}{l}1 \\
0\end{array}$ & 8 & 9 & 9 & 9 & 9 & 1 & 2 & 8 & 9 & $\begin{array}{l}2 \\
6\end{array}$ \\
\hline Alumínio & 7 & 5 & $\begin{array}{l}1 \\
0\end{array}$ & 6 & 7 & 8 & 7 & $\begin{array}{l}1 \\
0\end{array}$ & 1 & 2 & 7 & $\begin{array}{l}1 \\
0\end{array}$ & $\begin{array}{l}1 \\
7\end{array}$ \\
\hline RESULTADO & - & + & + & & + & $\begin{array}{l}+ \\
*\end{array}$ & + & - & - & $\overline{-}$ & $\begin{array}{l}+ \\
*\end{array}$ & $\overline{-}$ & \\
\hline
\end{tabular}

Quadro 2 - Pontuação estabelecida de acordo com cada material selecionado

Fonte: Azambuja et al. (2008). 
GRC é a sigla utilizada para denominar o compósito formado por uma matriz cimentícia (pasta de cimento com ou sem agregado miúdo) reforçada com fibras de vidro dispersas. Uma das principais características desse material é a alta resistência mecânica, a reduzida espessura e a grande moldabilidade, devido à fluidez que o material apresenta quando aplicado, necessária para que possa ser projetado e tome forma em um molde. Existem diversos métodos de produção e projeção desse material, contudo, neste trabalho, são apresentados apenas aqueles utilizados pela empresa que produziu os componentes (LAMEIRAS, 2007).

\section{Seleção geométrica}

Assim como na definição do material, os requisitos foram considerados na escolha da geometria mais adequada do EC, como se pode visualizar no Quadro 3, que apresenta o exemplo de um dos requisitos utilizados. Nesse quadro foram identificadas as informações necessárias para a resolução geométrica de cada um dos requisitos (Quadro 3) e as diferentes possibilidades de solução das funções (Quadro 3). Com base nesses dados foram modelados alguns possíveis arranjos formais do EC (Quadro 3), gerando condições para o desenvolvimento de simulações computacionais de diferentes arranjos do elemento.

A partir da utilização dessa metodologia, iniciaram-se algumas definições formais, tais como:

(a) divisão do elemento em quatro partes, que devem atuar monoliticamente; (b) encaixe entre as partes do tipo espiga e recesso;

(c) dimensões compatíveis com a modulação da alvenaria estrutural;

(d) outras de cunho conceitual, como, por exemplo, a inclusão de diferentes funções num mesmo componente (estrutural e funcional); e

(e) a identificação e a utilização de limites naturais entre os componentes fixos e móveis, especialmente a eliminação de fronteiras entre os componentes fixos da alvenaria e da esquadria.

\section{Simulação computacional via elementos finitos}

A partir dessas definições iniciais foram realizadas simulações de comportamento estrutural do elemento, via método de elementos finitos. As simulações buscaram identificar os pontos com maior incidência de cargas na alvenaria, considerando para isso o terceiro andar de um total de sete pavimentos.

Na Figura 1, pode ser visualizado o modelo com o cruzamento das tensões nos eixos x e y. Nessa simulação verifica-se a clara concentração de tensões nos cantos dos vãos, justificando assim a utilização de prolongamentos nas vergas e contravergas. Essas extensões de verga e contraverga buscam distribuir de forma mais uniforme as forças atuantes nos vértices das aberturas, reduzindo o acúmulo de tensões e evitando o surgimento de patologias nessas áreas.

\begin{tabular}{|l|l|l|}
\hline \multicolumn{1}{|c|}{ REQUISITO } & \multicolumn{1}{|c|}{ OPÇÕES } & \multicolumn{1}{c|}{ INFORMAÇÕES NECESSÁRIAS } \\
\hline Gabarito do vão & $\begin{array}{l}\text { 1) nível e prumo fornecidos } \\
\text { pelo EC } \\
\text { 2) dimensões do vão } \\
\text { fornecidas pelo EC }\end{array}$ & $\begin{array}{l}\text { - sequência ideal de execução (EC monolítico e partido) } \\
\text { - peso do EC monolítico e necessidade de partição } \\
\text { - possibilidades do GRC para geometrias complexas } \\
\text { - possibilidade de ligação estrutural entre partes }\end{array}$ \\
\cline { 3 - 3 } & & OPÇÕES DE GEOMETRIA \\
\cline { 3 - 3 }
\end{tabular}

Quadro 3 - Método de seleção de geometrias utilizado na pesquisa

Fonte: Azambuja et al. (2008). 


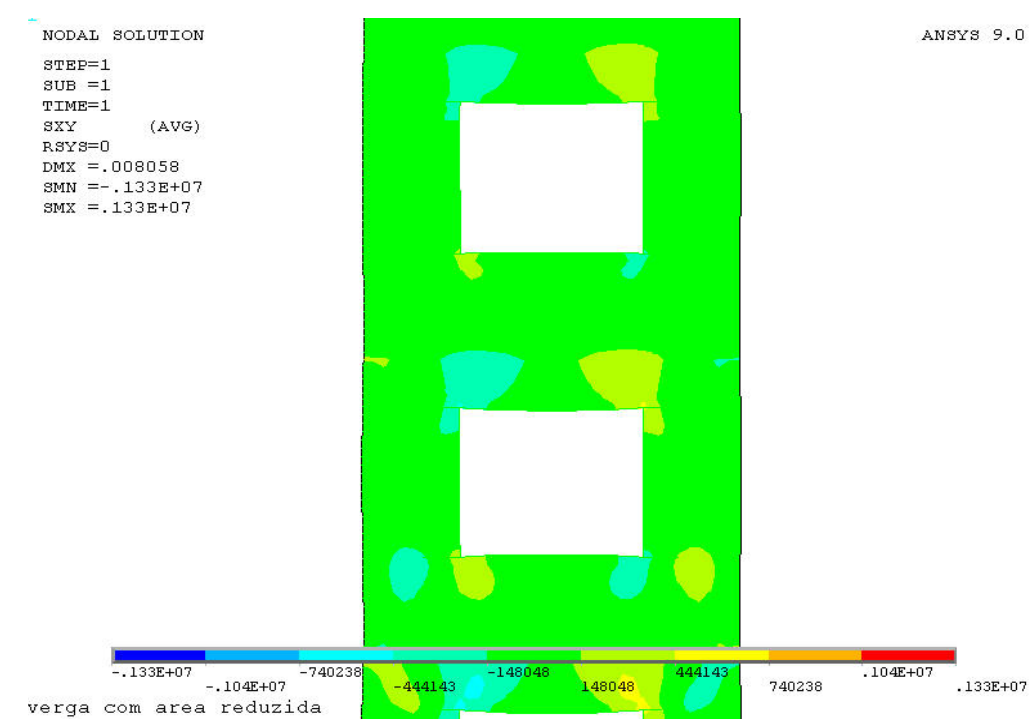

Figura 1 - Simulação de comportamento estrutural considerando os eixos $X$ e $Y$

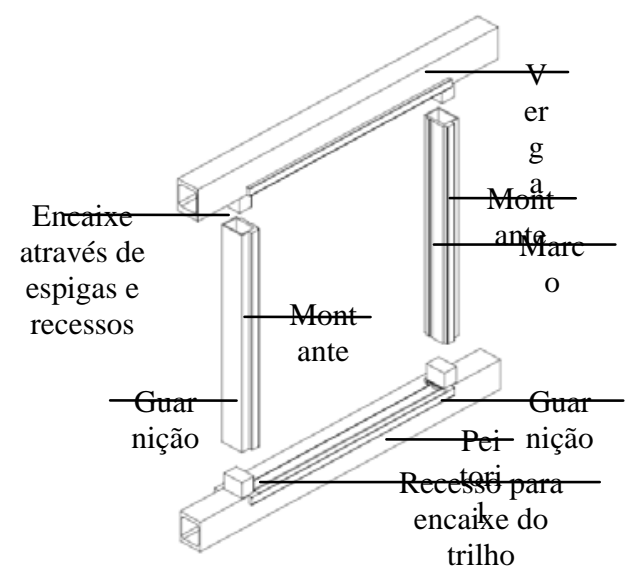

Figura 2 - Vista interna do primeiro protótipo virtual do EC

\section{Solução adotada}

As definições acima apresentadas geraram subsídios para que o EC fosse definido como um elemento formado por quatro componentes principais de GRC, que se encaixam através de espigas e recessos (Figura 2) e atuam na interface esquadria-alvenaria, conforme visualizado na Figura 3.

A solução é composta de dois componentes horizontais, um superior (verga) e outro inferior (contraverga), e de dois verticais (montantes), que fazem a conexão entre a verga e a contraverga. Os trilhos utilizados são produzidos em poliéster pultrudado (plástico reforçado com fibras), e as folhas (componentes móveis da solução) podem ser de materiais tradicionais como alumínio, madeira, PVC, etc. Nesta pesquisa foram utilizadas como elementos móveis duas folhas de correr com perfis de alumínio e vidro de $4 \mathrm{~mm}$. 


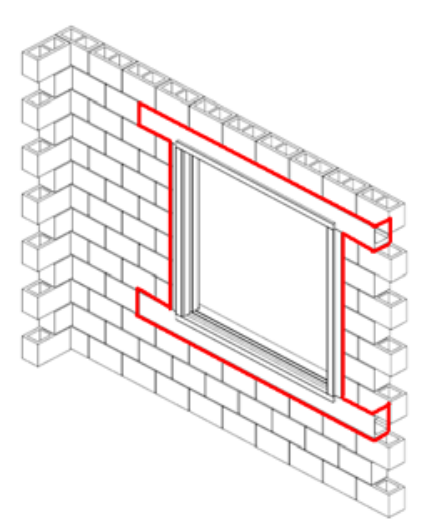

Figura 3 - Vista externa do EC atuando na interface esquadria-alvenaria

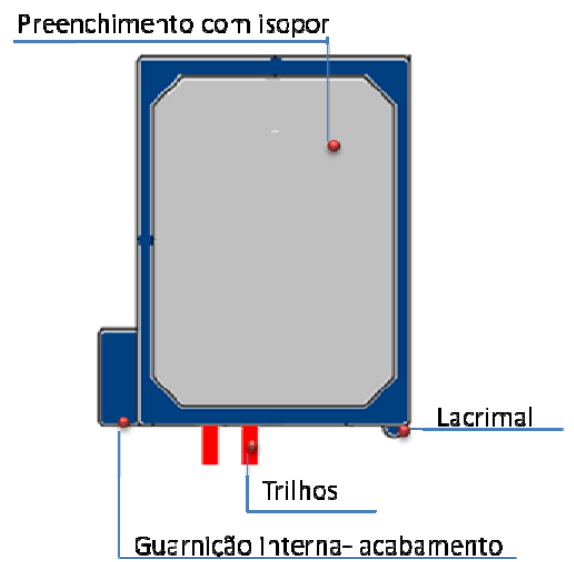

Figura 4 - Seção da verga

\section{Produção de protótipos}

Inicialmente, a equipe desenvolveu um protótipo virtual em CAD, em que foram mais bem visualizadas e definidas as funções, dimensões e formas de encaixe do conjunto e de cada componente do EC.

A verga é o componente horizontal superior do elemento, apresenta seção retangular compatível dimensionalmente com os blocos estruturais e é preenchida com poliestireno expandido (EPS). Esse componente desempenha funções estruturais de sustentação do vão e funções construtivas, já que incorpora a parte superior do caixilho fixo da esquadria, um lacrimal para o adequado descolamento das águas da chuva e o acabamento na face interna. É nele que são fixados os trilhos superiores, para o adequado funcionamento da esquadria (Figura 4).

A contraverga, cuja seção pode ser visualizada na Figura 5, é o componente horizontal inferior do conjunto. Desempenha a função estrutural de absorver as tensões de tração na parte inferior do vão e a função construtiva de incorporar a parte inferior da esquadria, com a pingadeira na face externa e um componente de acabamento na face interna. Nesse componente são fixados os trilhos inferiores.

Os montantes são os componentes verticais, com função estrutural de absorver os esforços que ocorrem na alvenaria nas laterais do vão, recebendo as cargas da verga e transmitindo-as para a contraverga. Construtivamente, os montantes absorvem as funções da esquadria no encaixe das folhas móveis e de acabamento, incorporando um detalhe na face interna (AZAMBUJA et al., 2008).

Na verga e na contraverga encontram-se recessos para a fixação dos trilhos através de material aderente. Os trilhos são perfis de plástico (poliéster) reforçado com fibras, conformados através do processo de pultrusão. Esse processo consiste na produção contínua de perfis plásticos de alto desempenho, utilizando para isso resinas específicas com reforços de fibras flexíveis (PULTRUSÃO..., 2010).

A partir dessa nova definição funcional e conceitual, que busca integrar a alvenaria à 
esquadria, adotou-se uma nova denominação para o conjunto: elemento de integração (EI).

Ante o sistema convencional de construção, em que as vergas e contravergas desempenham o papel estrutural, enquanto a esquadria - marco, contramarco, batente, guarnição, folhas e peitoril desempenha a função de habitabilidade dos ambientes, o EI representa uma nova solução de produto e processo construtivo, já que alia, em um único elemento, funções estruturais (verga e contraverga), de fechamento e de funcionamento da esquadria (trilhos, batentes, guarnição), com montagem através de encaixes, utilizando um material não convencional (GRC) para esse fim.

A partir da definição geométrica e funcional do elemento, foi desenvolvido um modelo de construção virtual, buscando identificar os benefícios e barreiras a partir da utilização do EI, bem como definir as sequências construtivas envolvidas no processo de construção.

A sequência de execução utilizada na construção de uma parede com a nova solução tem início de forma idêntica ao processo tradicional de construção, com a construção das três primeiras fiadas (Figura 6a), utilizando blocos cerâmicos (ou de concreto) e argamassa de assentamento.

Nesta pesquisa, foram utilizados blocos com as seguintes dimensões (c x l x h): 29 cm x 14 cm x
$19 \mathrm{~cm}$ para bloco inteiro, e $14 \mathrm{~cm}$ x $14 \mathrm{~cm}$ x $19 \mathrm{~cm}$ para meio bloco. A argamassa utilizada foi a do tipo industrializada, dada a crescente utilização desse tipo de material pelas vantagens ligadas à racionalização do canteiro e à garantia da homogeneidade e qualidade do produto, além de minimização de perdas de materiais e redução de prazos (REGATTIERI; SILVA, 2010; RIBAS; CARVALHO JUNIOR, 2007). A partir da conclusão da terceira fiada, inicia-se a montagem do elemento com a fixação da contraverga sobre a argamassa, devendo ser verificados o nível e o prumo do componente para correto desenvolvimento da montagem (Figura 6b).

Em seguida, precisam ser encaixados os dois montantes (Figura 6c), devendo-se utilizar uma cola nas espigas para o correto encaixe dos elementos e para que trabalhem de forma monolítica. Esses componentes também servem como guia para o levantamento da parede.

Após a fixação dos componentes verticais, finaliza-se a montagem do elemento com o encaixe da verga sobre os recessos dos montantes (Figura 6d), e, da mesma forma que na parte inferior, devese utilizar um material fluido aderente que garanta a união desses componentes. Para que essa atividade seja adequadamente desenvolvida, é necessária a montagem de andaimes, para a colocação da verga na parte superior do vão.

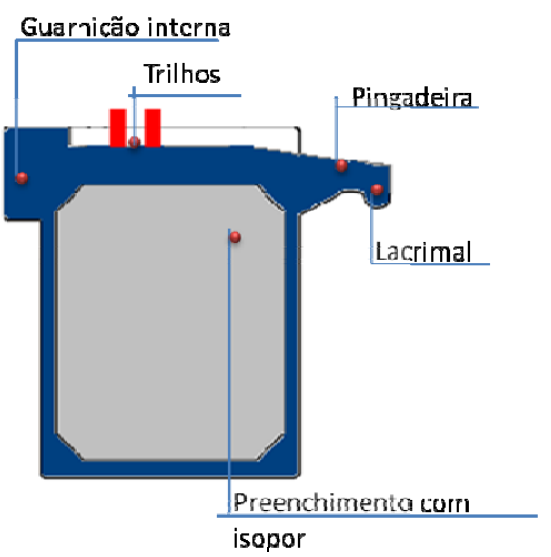

Figura 5 - Seção da contraverga 


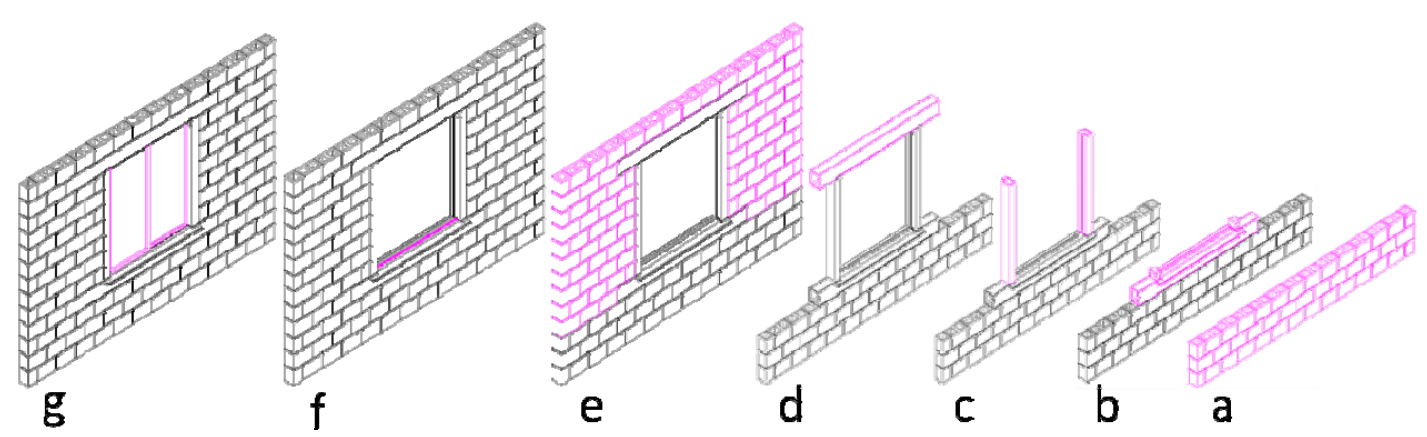

Figura 6 - Sequência construtiva modelada utilizando o EC

Além de servir como gabarito para o vão, com definição do nível e do prumo da janela, a utilização do EI exclui a necessidade de utilização de equipamentos de transporte e içamento, devido à compatibilidade de peso dos componentes para a movimentação e instalação manual, além de evitar os retrabalhos e erros de dimensionamento dos vãos e de instalação deficiente da janela, que ocorrem frequentemente na tecnologia tradicional.

Após a montagem completa do EI, dá-se continuidade ao erguimento dos panos de parede laterais e superior à verga (Figura 6e), sempre com o auxílio de andaimes, finalizando, dessa forma, os trabalhos construtivos relacionados ao sistema estrutural.

A partir dessa etapa, pode-se realizar o fechamento completo do envelope da edificação, o que pode ser feito por meio de mecanismos temporários ou dos componentes móveis das esquadrias, permitindo, assim, que atividades internas e de acabamento sejam realizadas sem a influência das condições climáticas ou perigos relacionados ao vandalismo.

A etapa de colocação dos trilhos e folhas de janela também pode ser realizada o mais tardiamente possível, necessitando apenas a fixação dos trilhos pululados nos locais predeterminados pela geometria (Figura 6f). Essa fixação deve ser realizada com material colante que garanta a perfeita aderência entre a verga, a contraverga e os trilhos. Da mesma forma, no caso de janelas de correr (as mais utilizadas), as folhas precisam ser apenas encaixadas nos trilhos (Figura 6g), e a partir desse encaixe é feito o travamento para que não possam ser retiradas pela face externa.

Diante do sistema tradicional de construção, a utilização do EI exclui a necessidade de instalação de peitoril e de execução de vergas e contravergas, bem como os trabalhos relacionados a essa atividade, como preparação de fôrmas, escoras, armadura, graute e espera de tempo de cura dos materiais. Além destes, reduz os passos e partes necessários na instalação da esquadria, como chumbamento do contramarco, colocação de arremates e a necessidade de equipamentos e materiais diferenciados para a instalação da esquadria, tais como furadeira e silicone. Nessa modelagem também puderam ser observadas questões relacionadas à coordenação modular, conectividade do elemento e do conjunto, bem como da viabilidade construtiva.

Com a definição do projeto e a modelagem da sequência construtiva, verificou-se a necessidade de construção de um protótipo físico para análise inicial de viabilidade do EI, antes da moldagem em GRC. Dessa forma foi produzido um primeiro modelo, em MDF, na escala real, com o objetivo de verificar aspectos dimensionais, de transporte e de construtibilidade.

O EI foi montado iniciando-se pela contraverga, com posterior encaixe dos montantes (Figura 7), e finalmente da verga, conforme apresentado na Figura 8. Com o conjunto pronto, foram encaixados e colados os trilhos pululados, e encaixadas as folhas de alumínio (Figura 9), finalizando a montagem do modelo em MDF (Figura 10). Durante o processo de montagem foram observados aspectos relacionados ao encaixe entre os elementos, e destes com os trilhos e folhas.

A partir da repetição do processo de montagem foram realizadas algumas sugestões de modificações que incluem a modificação da geometria dos encaixes, com a adoção de inclinação e não de arestas ortogonais, a utilização de chanfro em alguns cantos para facilitar a desmoldagem e evitar arestas vivas que poderiam sofrer danos, o rebaixamento da cota do trilho superior e a redução das paredes dos componentes em GRC. Nessa mesma verificação foram mantidas as características de divisão do elemento em quatro componentes, de incorporação das diversas funções num mesmo componente e de encaixe por meio de espigas. 


\section{Figura 7 - Encaixe do montante}
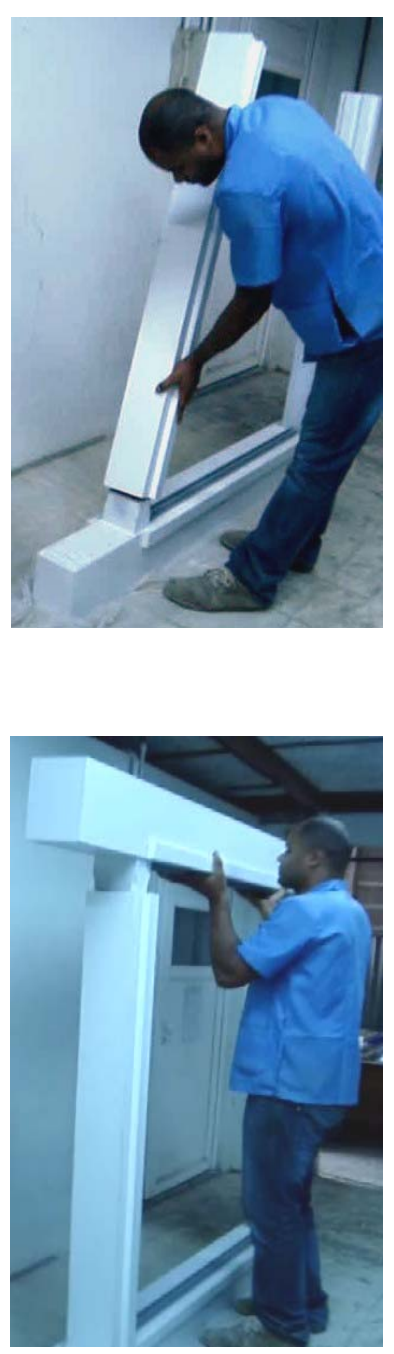

Figura 8 - Colocação da verga

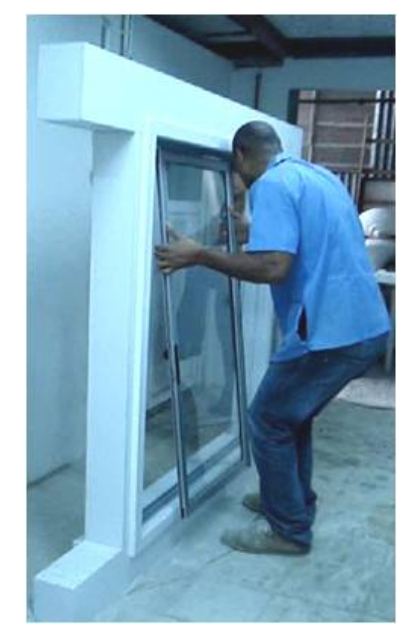

Figura 9 - Instalação dos componentes móveis 
Figura 10 - Protótipo do El em MDF
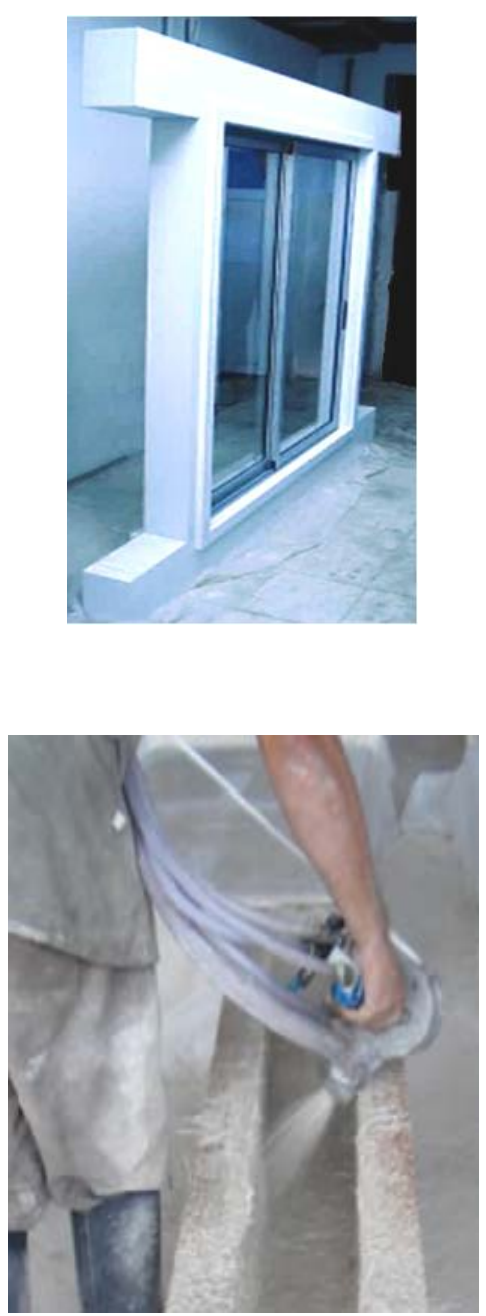

Figura 11 - Projeção do GRC em molde

Essas modificações foram inicialmente aplicadas em um modelo virtual 3D e posteriormente no primeiro protótipo em GRC (Figura 13). Esse protótipo foi produzido por uma indústria de préfabricados especialista na fabricação e aplicação de GRC. Dessa forma, os materiais e as técnicas de produção descritos neste trabalho se limitam àqueles utilizados pela empresa.

Para a produção inicial foi necessária a confecção de fôrmas de madeira, onde o GRC foi projetado e tomou forma. Essas fôrmas receberam aplicação de desmoldante para facilitar a desforma após a cura dos componentes.

A produção dos componentes iniciou-se com a produção da matriz cimentícia através da mistura dos agregados miúdos (de origem quartzosa e distribuição granulométrica adaptada aos equipamentos de projeção), do aglomerante (cimento branco CPB40), das adições pozolânicas, do aditivo superplastificante e da água em uma argamassadeira, segundo a dosagem estipulada pelos profissionais responsáveis pela fabricação do GRC. Essa matriz estava suficientemente fluida para ser bombeada através dos dutos até a pistola de projeção, onde, juntamente com as fibras de vidro álcali-resistentes (do tipo $\mathrm{AR}$ ) cortadas em tamanhos predeterminados pelo próprio equipamento (Figura 11), foi projetada na forma de spray, mediante o uso de ar comprimido, sobre os moldes.

O GRC foi projetado em finas camadas de $3 \mathrm{~mm}$ a $4 \mathrm{~mm}$, até atingir a espessura especificada, sendo cada camada compactada através da passagem de um rolo espiralado (Figura 12) antes da projeção da próxima camada. Após a compactação de cada uma das camadas foi feito o controle da espessura através da utilização de um medidor específico, visualizado na Figura 13, até atingir a dimensão total especificada em cada componente. 


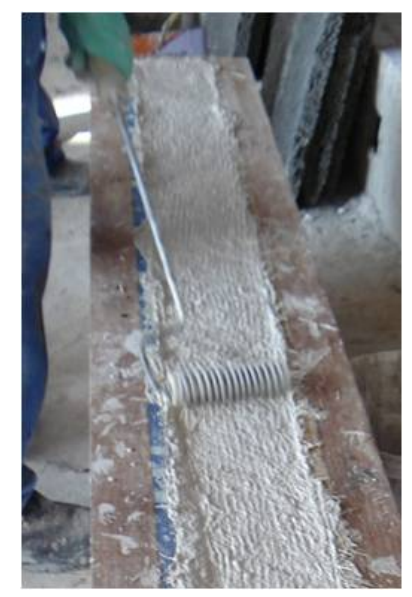

Figura 12 - Compactação com rolo espiralado

Figura 13 - Medidor de espessura

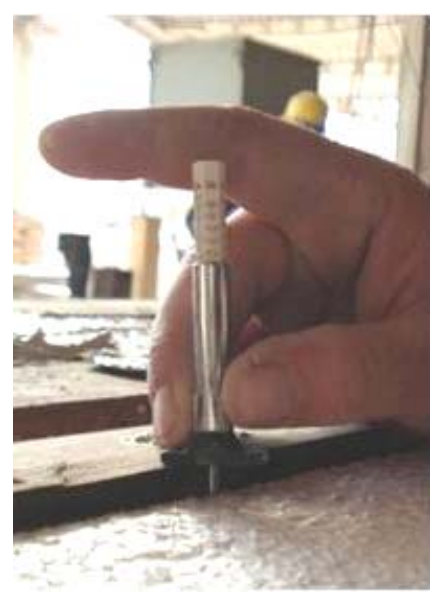

\begin{tabular}{|l|c|}
\hline \multicolumn{1}{|c|}{ Componente } & Massa (kg) \\
\hline Verga & 46,40 \\
\hline Montante direita & 18,87 \\
\hline Montante esquerda & 18,24 \\
\hline Contraverga & 43,60 \\
\hline
\end{tabular}

Quadro 4 - Massa dos componentes que compõem o EI

Após 2 dias, os componentes foram desmoldados, limpos e pesados (Quadro 4). Nesta etapa verificou-se que os montantes poderiam ser manipulados individualmente por apenas um trabalhador, enquanto a verga e a contraverga necessitavam dois operários para seu adequado manuseio.

O processo de montagem do elemento em GRC seguiu a sequência utilizada na montagem do protótipo em MDF, iniciando pela contraverga, passando pelo encaixe dos montantes (Figura 14) e terminando com a verga (Figura 15). Em seguida foram fixados os trilhos e instaladas as folhas de alumínio para verificar a conformidade com o projeto e o desempenho do EI (Figura 16).
A partir da montagem, a equipe do projeto identificou a necessidade de algumas modificações, tais como:

(a) a alteração das formas dos encaixes, para evitar trocas nas posições dos componentes;

(b) mudanças nos apoios do montante tanto na verga quanto na contraverga, através da redução de reentrâncias e saliências, visando a uma melhoria no desempenho geral;

(c) utilização de chanfro em todas as arestas; e

(d) a simplificação do montante, com menos reentrâncias, proporcionando economia de material sem afetar o desempenho. 


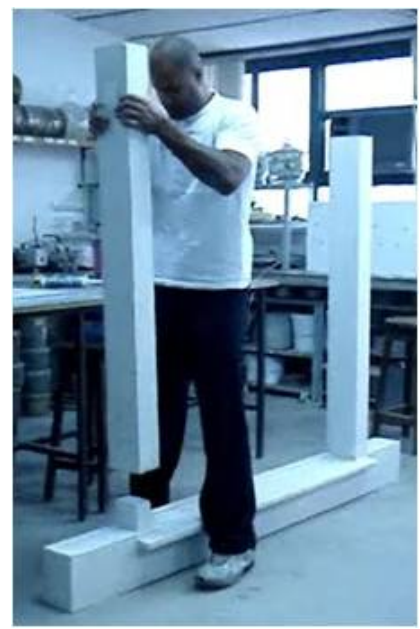

Figura 14 - Colocação do montante

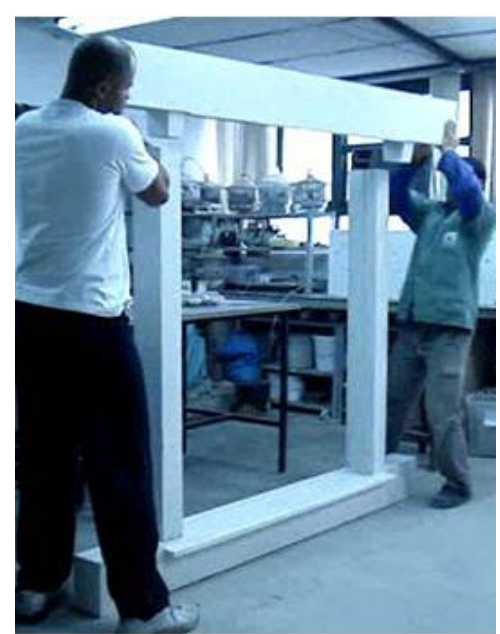

Figura 15 - Encaixe da verga

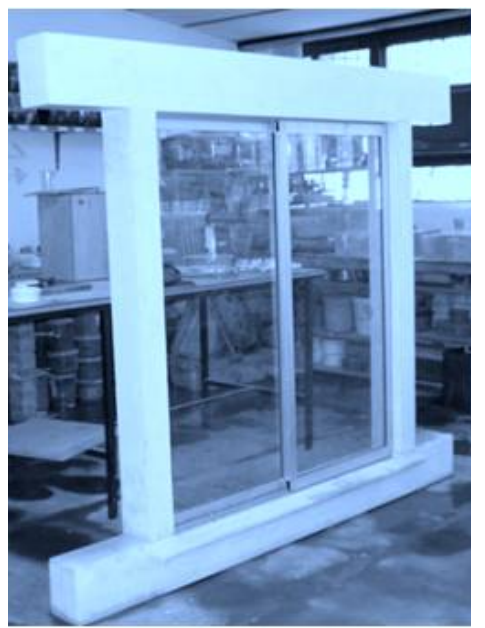

Figura 16 - Protótipo completo em GRC

Vários aspectos foram mantidos, tais como:

(a) a utilização do GRC nos componentes; (b) o plástico pultrudado nos trilhos; e

(c) o peso e as formas adequadas para manipulação dos componentes pelos operários. 
(d) A partir dessas considerações foram modificados os aspectos assinalados e modelado um novo desenho em 3D (Figura 17).

(e) Essas modificações foram apresentadas à empresa que produziu o GRC e novas considerações foram feitas sobre as formas dos encaixes, que novamente foram modificadas, já que apresentavam formas complexas, o que poderia comprometer a desmoldagem, devido à fragilidade das arestas dos componentes. Dessa forma, os encaixes foram modificados conforme apresentado na Figura 18.

\section{(f) Construção experimental}

A partir da definição geométrica, os componentes foram moldados, seguindo as especificações apresentadas na produção do primeiro protótipo em GRC, e utilizados para a confecção de uma parede de 3,40 m x 2,60 m, utilizada para verificar o desempenho estrutural do conjunto e a facilidade de construção e adaptação dos operários ao novo sistema, bem como a integração do elemento ao sistema construtivo. A equipe de construção era formada por dois operários, sem prévio treinamento, sendo a principal preocupação com o aprendizado do trabalho e com o desenvolvimento da sequência construtiva utilizando a nova solução.

A parede foi construída sobre uma base sólida (viga metálica) e sob um pórtico, para a realização posterior de ensaio estrutural. $\mathrm{O}$ processo executivo seguiu o esquema modelado na etapa intermediária deste trabalho.

Inicialmente foram executadas as três primeiras fiadas, utilizando blocos estruturais cerâmicos e argamassa industrializada, e, em seguida, a contraverga foi assentada sobre a seção de parede edificada. Nesse momento o nível e o prumo foram verificados e ajustados (Figura 19). O passo seguinte foi encaixar os montantes utilizando um material líquido colante nas espigas, para que o conjunto trabalhasse estruturalmente de forma monolítica (Figura 20).
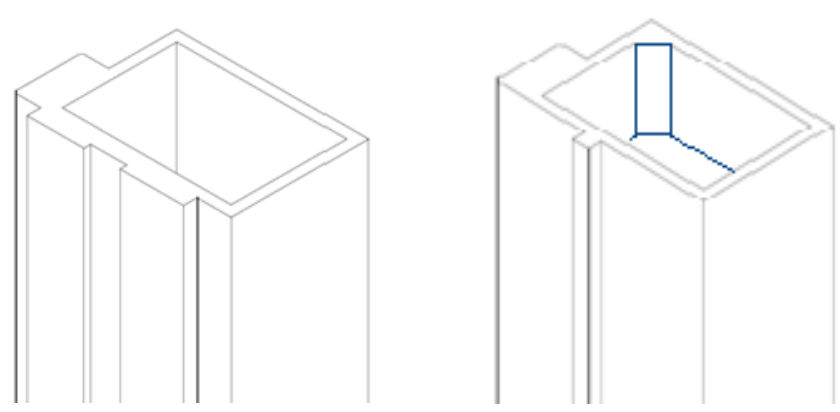

Figura 17 - Novas modificações nos montantes do EI

Nota: à esquerda, antiga configuração do componente, e à direita, nova configuração formal dos componentes verticais em GRC.

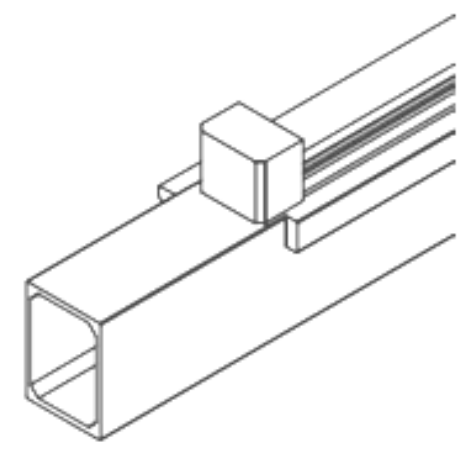

Figura 18 - Solução geométrica final para espigas da verga e da contraverga 


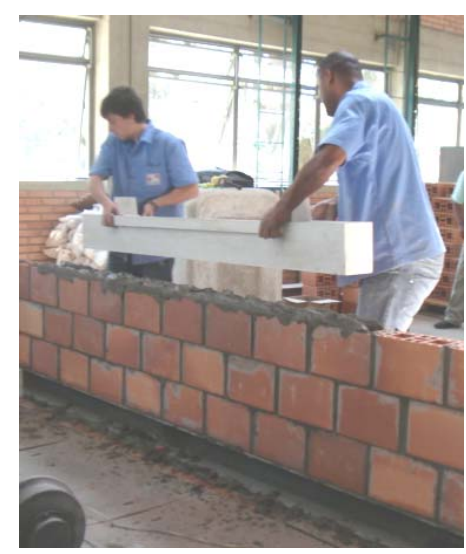

Figura 19 - Assentamento da contraverga

Figura 20 - Encaixe dos montantes
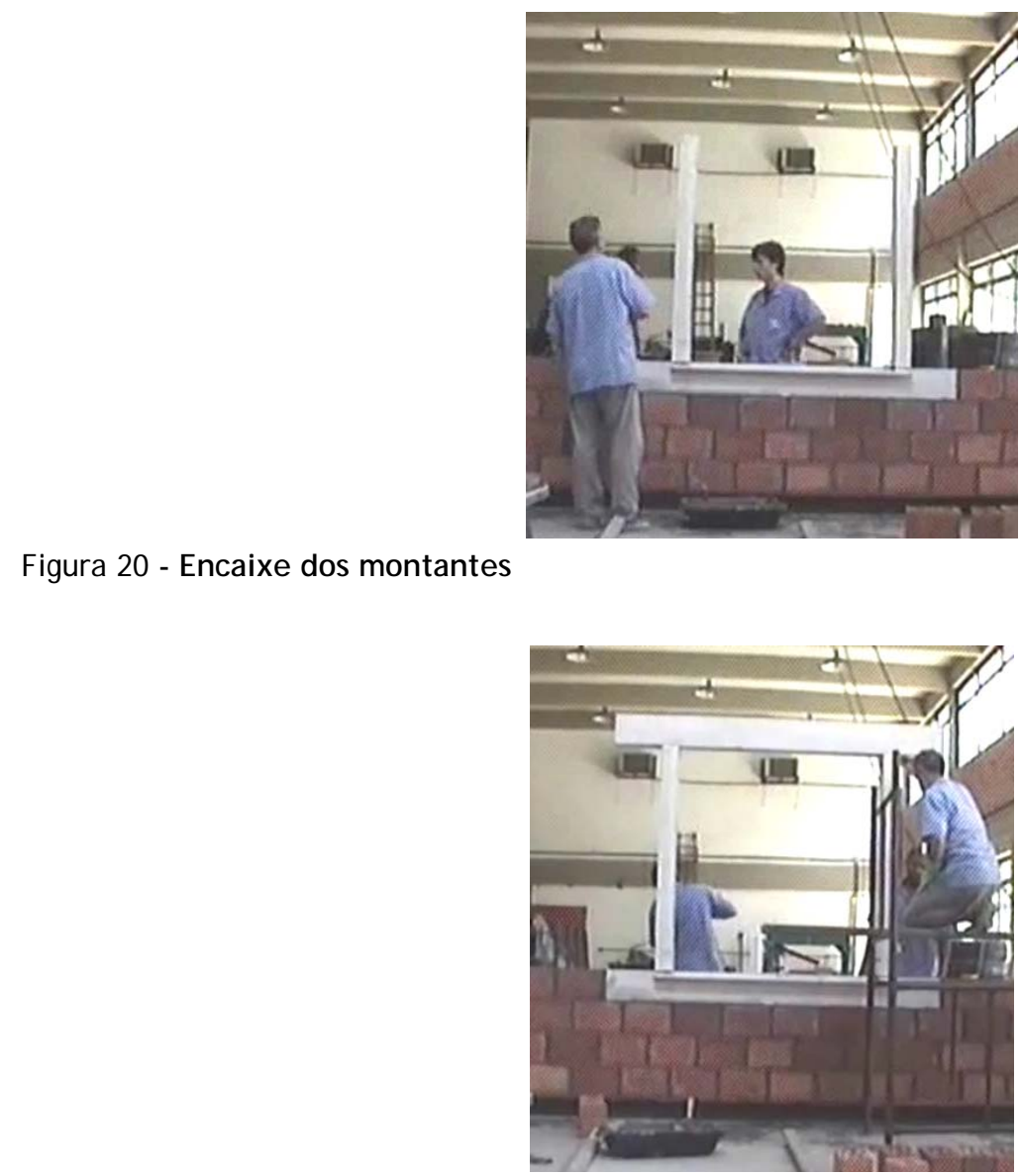

Figura 21 - Encaixe da verga

Em seguida foi encaixada a verga, quando também foi utilizado o material colante, buscando o mesmo desempenho solidário entre os elementos (Figura 21).

Para realizar essa atividade foi necessária a montagem de andaime. A seguir, deu-se prosseguimento à atividade de execução de alvenaria, até o completo preenchimento lateral e superior do vão (Figura 22).

\section{Conclusões}

A metodologia desenvolvida por Azambuja et al. (2008) e aplicada no desenvolvimento do elemento de conexão demonstrou-se adequada ao desenvolvimento de novos produtos, resultando em novas soluções diferenciadas, visto que foi aplicada em outros trabalhos (MOCH, 2008) e resultou em soluções também adequadas, mas diferentes da proposta neste trabalho. 


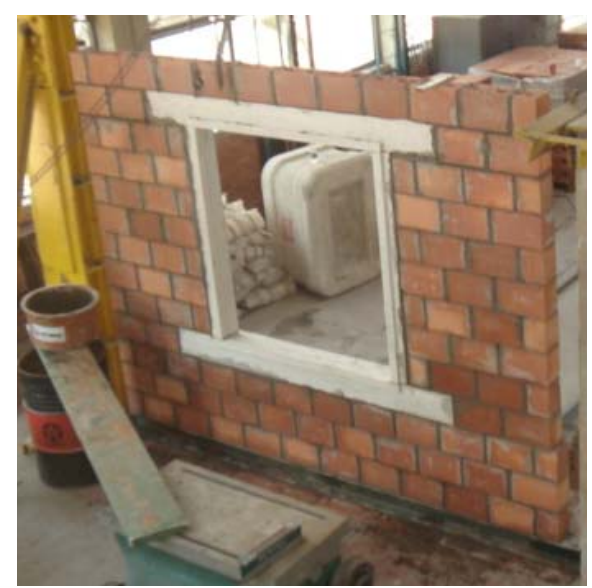

Figura 22 - Parede finalizada

O desenvolvimento, o refinamento, a modelagem e a produção de uma nova solução construtiva demonstraram a aplicabilidade do elemento de integração (EI), verificada através da compatibilidade dimensional, construtiva e funcional do conjunto.

Durante a modelagem puderam ser identificados aspectos relacionados à funcionalidade, conectividade, segurança no uso e operação, e construtibilidade, que foram verificados posteriormente nas etapas construtivas, seja durante a montagem laboratorial dos protótipos ou na construção experimental da parede.

Quanto à funcionalidade, o EI demonstrou-se adequadamente solucionado, visto que, após a montagem dos protótipos, as operações de abertura e fechamento das folhas podiam ser desenvolvidas com naturalidade. Já a conectividade pode ser verificada nos encaixes entre a alvenaria e o EI (dada a correta modulação e padronização), entre os componentes e os trilhos, entre as folhas e os componentes, e entre os trilhos e as folhas.

A segurança no uso e operação ocorreu pelas modificações realizadas nas etapas iniciais de modelagem, tais como: utilização de chanfros, evitando formas cortantes e perfurantes; e redução da espessura dos componentes, reduzindo assim o peso e permitindo maior facilidade no transporte, manipulação e instalação do conjunto.

Quanto à construtibilidade, puderam ser verificados aspectos relacionados à moldabilidade, através da análise da textura e da geometria dos componentes, e de montabilidade do EI, através da montagem e do correto encaixe do conjunto nos diferentes protótipos produzidos. Além disso, foi possível identificar a substancial redução no número de partes e passos, se comparado ao sistema tradicional de construção com vergas, contravergas e instalação de esquadrias de alumínio.

\section{Referências bibliográficas}

ALEXANDRE, I. F. Fissuras em Empreendimentos Habitacionais de Baixa Renda Executados em Alvenaria Estrutural: uma análise da relação causa e efeito. $171 \mathrm{f}$. Porto Alegre, 2008. Dissertação (Mestrado em Engenharia Civil) - Escola de Engenharia Civil, Universidade Federal do Rio Grande do Sul, Porto Alegre, 2008.

ALY, V. L. C.; SABBATINI, F. H. Determinação da Capacidade Resistente do Elemento Parede de Alvenaria Armada de Blocos de Concreto, Submetido a Esforço de Compressão. São Paulo: EPUSP, 1994.

\section{ASSOCIAÇÃO BRASILEIRA DE NORMAS}

TÉCNICAS. NBR 15575: edifícios habitacionais de até cinco pavimentos: desempenho. Rio de Janeiro, 2008.

AZAMBUJA, J. A. et al. Metodologia para Desenvolvimento de Produtos em Construção Ccivil. 40 f. 2008. In: COMPOHIS. Relatório do Projeto de Pesquisa FINEP/HABITARE/UFRGS. Porto alegre, 2008. . [Documento interno].

BRITO, J. Retroalimentação do Processo de Desenvolvimento de Empreendimentos de Habitação de interesse social a partir de reclamações de usuários: estudo no programa de arrendamento residencial. 157 f. Porto Alegre, 2009. Dissertação (Mestrado em Engenharia Civil) - Escola de Engenharia, Universidade Federal do Rio Grande do Sul, Porto Alegre, 2008. 
CÉSAR, C. G.; ROMAN, H. R.; Desenvolvimento de Um Processo Construtivo Racionalizado: painéis pré-fabricados com blocos cerâmicos. In: BONIN, L. C; AMORIN, S. R. L. (Ed.). Inovação Tecnológica na Construção Habitacional. Porto Alegre: Antac, 2006.

HOLANDA JÚNIOR, O. G. Influência de Recalques em Edifícios de Alvenaria Estrutural. 224 f. São Carlos, 2002. Tese (Doutorado em Engenharia Civil) - Escola de Engenharia de São Carlos, Universidade de São Paulo, São Carlos, 2002.

JOAQUIM, M. M. Flexão e Flexo-Compressão em Elementos de Alvenaria Estrutural. $194 \mathrm{f}$. São Carlos, 1999. Dissertação (Mestrado em Engenharia Civil) - Escola de Engenharia de São Carlos, Universidade de São Paulo, São Carlos, 1999.

LAMEIRAS, R. M. Contribuição ao Estudo das Propriedades dos Materiais Cimentícios Reforçados Com Fibras de Vidro (Glass Fibre Reinforced Cement - GRC). 255 f. Porto Alegre, 2007. Dissertação (Mestrado em Engenharia) Escola de Engenharia Civil, Universidade Federal do Rio Grande do Sul, Porto Alegre, 2007.

MAGALHÃES, E. F. de. Fissuras em

Alvenarias: configurações típicas e levantamento de incidências no Estado do Rio Grande do Sul. 180f. Porto Alegre, 2004. Dissertação (Mestrado em Engenharia Civil) - Escola de Engenharia, Universidade Federal do Rio Grande do Sul, Porto Alegre, 2004.

MEDEIROS, J. S.; SABBATINI, F. H. Alvenaria Estrutural Não Armada de Blocos de Concreto: produção de componentes e parâmetros de projeto. São Paulo: EPUSP, 1993.
MOCH, T. Estudo da Interface

Janela/Alvenaria: proposta de componente de conectividade. 178 f. Porto Alegre, 2009.

Dissertação (Mestrado em Engenharia Civil) Escola de Engenharia, Universidade Federal do Rio Grande do Sul, Porto Alegre, 2009.

PULTRUSÃO DO BRASIL. [Senso]. Disponível em:

$<$ http://www.pultrusao.com.br/senso/index.php/sit e/>. Acesso em: 08 out. 2010.

REGATTIERI, C. E.; SILVA, L. L. R. Ganhos Potenciais na Utilização da Argamassa Industrializada. Disponível em:

$<$ http://www.abai.org.br/images/ganhos\%20potenc iais.pdf>. Acesso em: 20 set. 2010.

RIBAS, L. C.; CARVALHO JUNIOR, A. N. Ganhos no Potencial Produtivo Através da Substituição de Argamassa de Revestimento Rodada em Obra por Industrializada em Sacos. In: ENCONTRO NACIONAL DE ENGENHARIA DE PRODUÇÃO, 27., Foz do Iguaçu, 2007. Anais... Foz do Iguaçu, 2007.

RICHTER, C. Qualidade da Alvenaria Estrutural em Habitações de Baixa Renda: uma análise da confiabilidade e da conformidade. $180 \mathrm{f}$. Porto Alegre, 2007. Dissertação (Mestrado em Engenharia Civil) - Escola de Engenharia, Universidade Federal do Rio Grande do Sul, Porto Alegre, 2007.

\section{Agradecimentos}

Agradecemos à FINEP, agência financiadora desta pesquisa, ao $\mathrm{CNPq}$, pelo auxílio financeiro durante o curso de mestrado, ao CIENTEC, pela cessão do local para a construção da parede experimental, à PULTRUSÃO DO BRASIL, pela doação dos perfis pululados e à SISCOBRÁS, pela produção dos protótipos em GRC.

Revista Ambiente Construído

Associação Nacional de Tecnologia do Ambiente Construído

Av. Osvaldo Aranha, 99 - 3o andar, Centro

Porto Alegre - RS - Brasil

CEP $90035-190$

Telefone: +55 (51) 3308-4084

Fax: +55 (51) 3308-4054

www. seer. ufrgs. br/ ambienteconstruido

E-mail: ambienteconstruido@ufrgs.br 